\title{
UPDATE ON SIC-BASED INVERTER TECHNOLOGY
}

\author{
Madhu Chinthavali ${ }^{1}$, Hui Zhang ${ }^{2}$, Leon M. Tolbert ${ }^{1,2}$, Burak Ozpineci ${ }^{1}$ \\ ${ }^{1}$ Oak Ridge National Laboratory \\ ${ }^{2}$ The University of Tennessee \\ Oak Ridge, TN 37831-6472 USA Knoxville, TN 37996-2100 USA
}

\begin{abstract}
This paper presents a study of Silicon Carbide (SiC) technology which includes device characterization and modeling, inverter simulation, and test results for several prototype inverters. The static and dynamic characteristics of discrete devices and half bridge modules are presented. Test results of a $55 \mathrm{~kW}$ hybrid inverter with SiC Schottky diodes and an $18 \mathrm{~kW}$ all-SiC inverter using $\mathrm{SiC}$ JFETs and Schottky diodes are demonstrated.
\end{abstract}

\section{Keywords - Inverter, Silicon carbide (SiC)}

\section{INTRODUCTION}

The role of power electronics in the electrical energy conversion sector is increasing by the decade [1]. Also, with the growth of power electronics as the interface for renewable technologies and motor drive technology, there is a need for efficient converters [2-4]. Device development of power devices is a critical aspect of the power electronic industry along with new topologies and control techniques. There is a revolutionary change with wide bandgap (WBG) materials making inroads into the power semiconductor device market.

Silicon carbide $(\mathrm{SiC})$ is in the forefront amongst the WBG material based devices. Efficiency comparisons of device level development of $\mathrm{SiC}$ have progressed from designing discrete level low amperage devices to building modules with scalable devices and higher ratings, especially current. This growth has enabled researchers to test modules for efficiency comparison with Silicon $(\mathrm{Si})$ counterparts and also build several converter and inverter prototypes. SiC discrete devices compared with $\mathrm{Si}$ devices have been reported showing the benefits of $\mathrm{SiC}$ devices. [5-7].

High temperature packaging was recognized as a necessary area to be developed in parallel with development of $\mathrm{SiC}$ technology, so that the benefits of the SiC devices can be more fully realized in several applications. WBG research at Oak Ridge National Laboratory is focused on the development of high efficiency, high temperature SiC based inverters for automotive and power system applications.

${ }^{1}$ Prepared by the Oak Ridge National Laboratory, Oak Ridge, Tennessee 37831, managed by UT-Battelle for the U.S. Department of Energy under contract DE-AC05-00OR22725.

The submitted manuscript has been authored by a contractor of the U.S. Government under Contract No. DE-AC05-00OR22725. Accordingly, the U.S. Government retains a non-exclusive, royalty-free license to publish from the contribution, or allow others to do so, for U.S. Government purposes.
Research involves work on high temperature packaging $\left(>200{ }^{\circ} \mathrm{C}\right)$, high temperature gate drive electronics, inverter design and prototype development, efficiency estimation with device and system simulation, and experiments.

This paper presents characterization and modeling of $\mathrm{SiC}$ Schottky diodes and SiC JFETs both as discrete devices as well as in half bridge modules. The discrete devices presented in this paper include normally-on $1200 \mathrm{~V}, 10 \mathrm{~A}$ SiC JFET; normally-off $1200 \mathrm{~V}, 10$ A SiC JFET; and a 600 $\mathrm{V}, 75$ A Schottky diode. The devices in modules that were characterized are SiC Schottky diodes in a $600 \mathrm{~V}, 450 \mathrm{~A}$ hybrid module (Si-IGBT, SiC Schottky diode) and $\mathrm{SiC}$ JFETs and Schottky diodes in a $1200 \mathrm{~V}, 30 \mathrm{~A}$ module. The hybrid ( $\mathrm{Si}$ and $\mathrm{SiC}$ Schottky diodes) $55 \mathrm{~kW}$ inverter prototype inverter test results will be discussed to see the difference in efficiencies when compared to Si-based inverters. Finally an $18 \mathrm{~kW}$ all-SiC inverter prototype with SiC JFETs and SiC Schottky diodes will be presented.

\section{DEVICE CHARACTERISTICS - DIODES}

This section presents characterization of $600 \mathrm{~V} / 75 \mathrm{~A}$ discrete SiC Schottky diode and $600 \mathrm{~V} / 450$ A hybrid module.

\section{A. Static Characteristics}

After extensive testing, $I-V$ characteristics of $600 \mathrm{~V} / 75 \mathrm{~A}$ diodes were obtained at different temperatures in the $-50^{\circ} \mathrm{C}$ to $175^{\circ} \mathrm{C}$ ambient temperature range (as shown in Fig. 1). Considering the piece-wise linear (PWL) model of a diode, which includes a dc voltage drop, $V_{D}$, and a series resistance, $R_{D}$, the diode $I-V$ curves can be approximated with the following equation:

$$
V_{d}=V_{D}+R_{D} \cdot I_{d}
$$

where $V_{d}$ and $I_{d}$ are the diode forward voltage and current, and $V_{D}$ and $R_{D}$ are the diode PWL model parameters.

Fig. 2 shows $R_{D}$ and $V_{D}$ values of the $600 \mathrm{~V} / 75 \mathrm{~A} \mathrm{SiC}$ Schottky diodes with respect to temperature. As seen in these figures, $V_{D}$ decreases with temperature and $R_{D}$ increases with temperature. Decrease in $R_{D}$ is a sign of the positive temperature coefficient the SiC Schottky diodes have, which implies that these devices can be paralleled easily.

\section{B. Dynamic Characteristics}

The SiC Schottky diode was also tested in a chopper circuit to observe its dynamic properties. The chopper was switched at $1 \mathrm{kHz}$ with a $40 \%$ duty cycle. The reverse recovery current waveforms obtained for different forward 


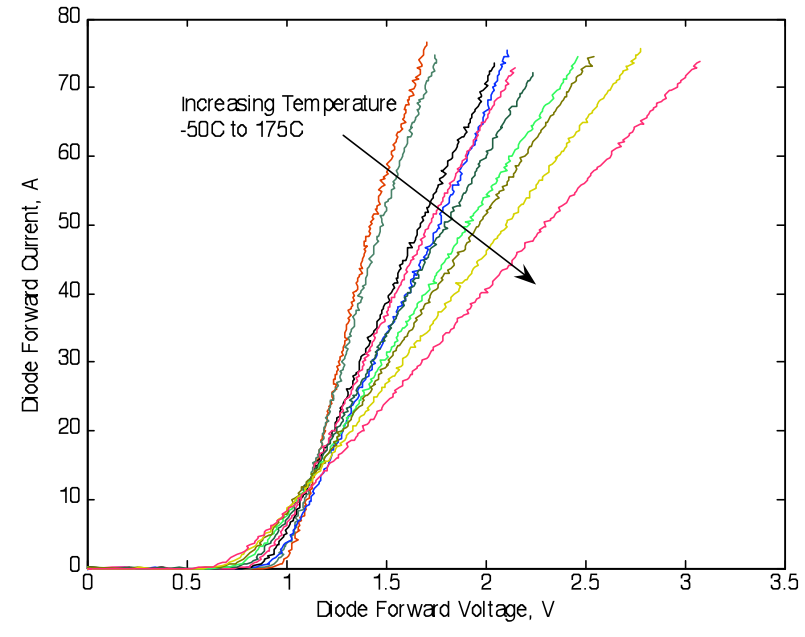

Fig. 1. Experimental I-V curves of the 75A SiC Schottky diode.

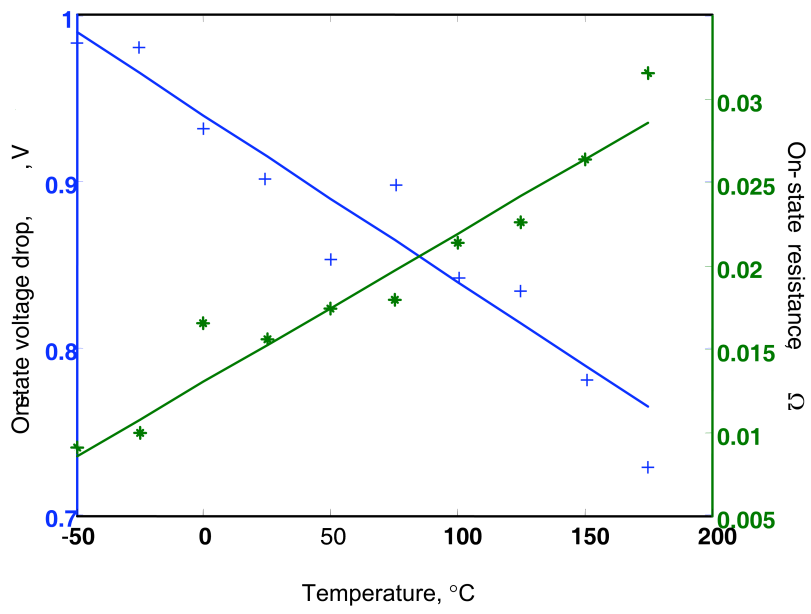

Fig. 2. $R_{D}$ and $V_{D}$ obtained from the experimental data.

currents are shown in Fig. 3. As seen in this figure, the reverse recovery current does not change with forward current. Note that theoretically, Schottky diodes do not display reverse recovery phenomenon.

\section{Comparison with a Si pn Diode}

The module used in this study has $600 \mathrm{~V} / 450 \mathrm{~A}$ diodes. For this reason, six $75 \mathrm{~A} \mathrm{SiC} \mathrm{Schottky} \mathrm{diodes} \mathrm{are} \mathrm{used} \mathrm{to}$ replace three $150 \mathrm{~A} \mathrm{Si}$ pn diodes. The static characteristics of the packaged $600 \mathrm{~V} / 450 \mathrm{~A} \mathrm{SiC} \mathrm{Schottky} \mathrm{and} \mathrm{Si} \mathrm{pn} \mathrm{diodes} \mathrm{at}$ room temperature are shown in Fig. 4. As seen in this figure, both of the diodes have similar characteristics. At low currents, the Si pn diode has lower voltage drop. At higher currents, the SiC Schottky diode has lower voltage drop; therefore, for higher power operation, SiC Schottky diodes will have lower conduction losses.

Switching losses of the $75 \mathrm{~A} \mathrm{SiC} \mathrm{Schottky} \mathrm{diode} \mathrm{have}$ been shown in Fig. 3. Similar tests have been done with the 150 A Si pn diodes. The results of these tests can be seen in Fig. 5. It can be observed that the peak reverse recovery current of the $\mathrm{Si}$ pn diode is much higher than that of the $\mathrm{SiC}$ Schottky diode at the same forward current and increases further with increasing forward current. This corresponds to high reverse recovery losses that increase with forward

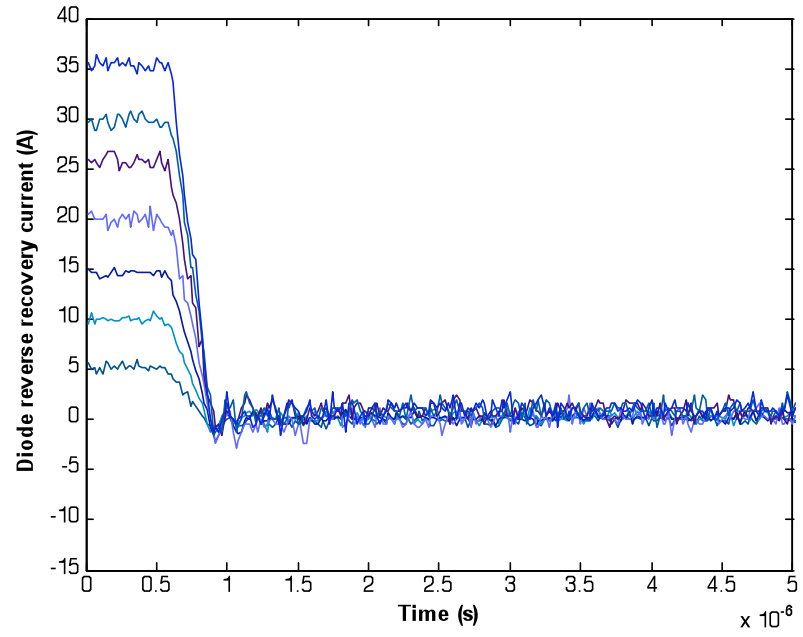

Fig. 3. Reverse recovery current waveforms of the SiC Schottky diode for different forward current values.

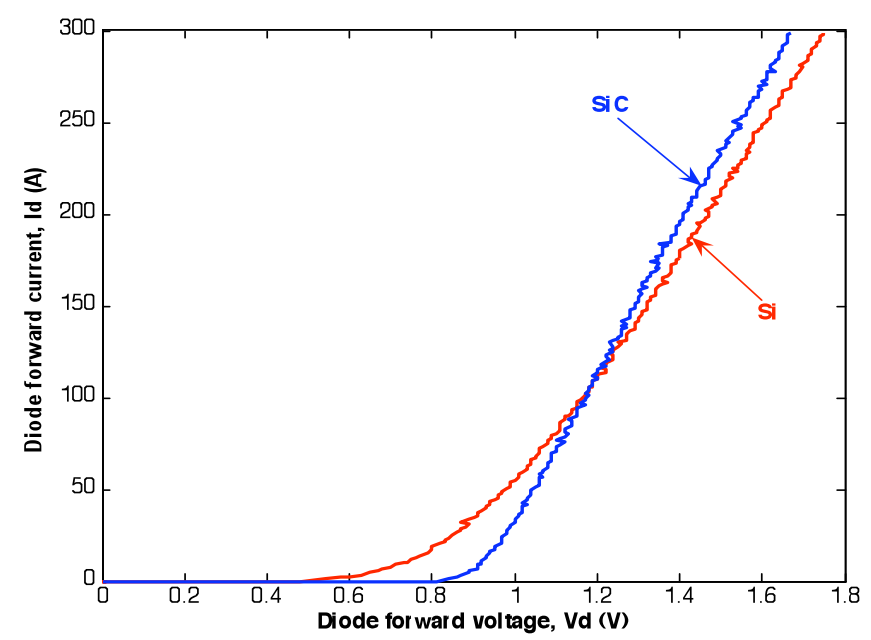

Fig. 4. The static characteristics of the packaged $600 \mathrm{~V} / 450 \mathrm{~A} \mathrm{SiC}$ Schottky and Si pn diodes at room temperature.

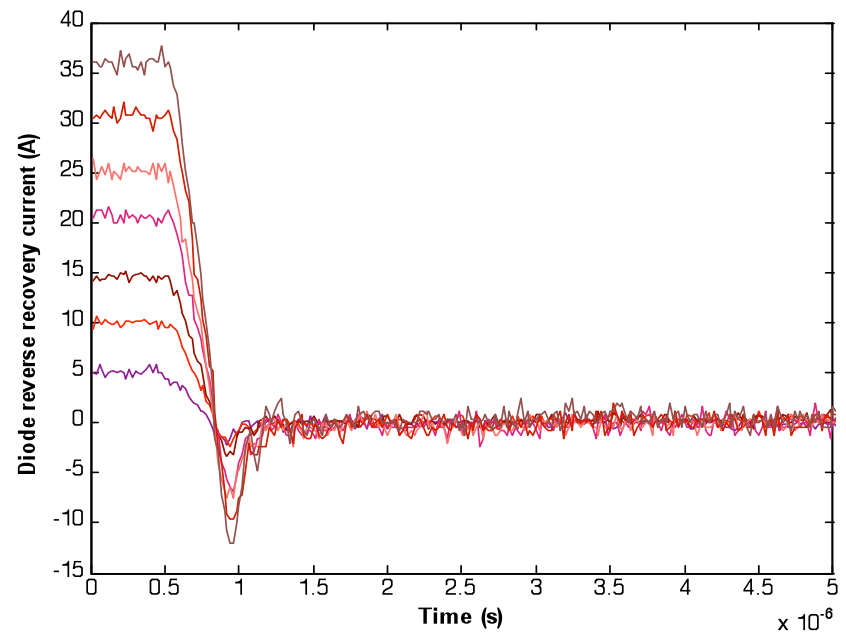

Fig. 5. Reverse recovery current waveforms of the Si Schottky diode for different forward current values. 
current. Fig. 6 shows the comparison of the energy losses per turn-off of a 75 A SiC Schottky diode and a $150 \mathrm{~V} \mathrm{Si} \mathrm{pn}$ diode. As the diode forward current increases, the energy losses of the Si pn diode increase exponentially while those of the SiC Schottky diode are negligible.

As a summary, the static characteristics of both of the tested diodes are similar; however, the dynamic characteristics are much different. Si pn diode has high peak reverse recovery currents that result in high diode switching losses and extra IGBT losses since the reverse current has to go through a main switch. Consequently, it is expected for the Si IGBT - SiC Schottky diode hybrid inverter to perform better than the similar all-Si inverter.

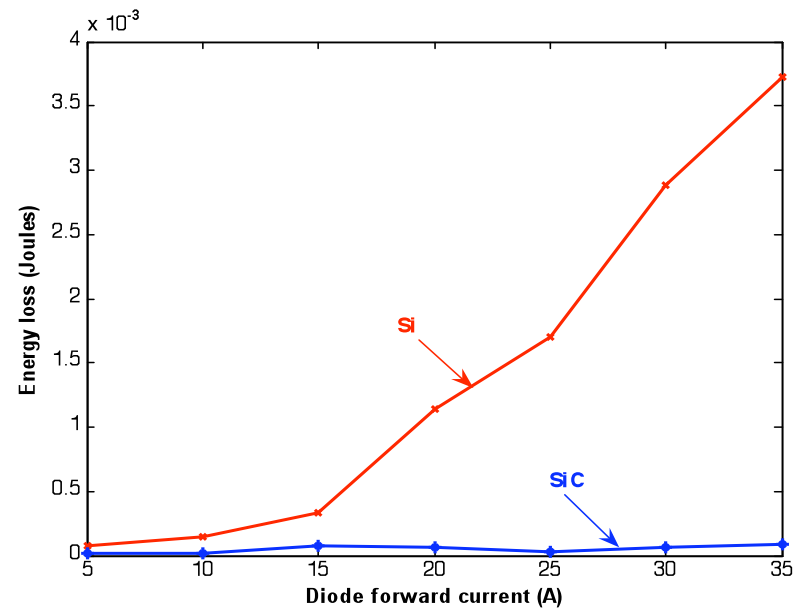

Fig. 6. Comparison of the energy losses per turn-off of a 75 A SiC Schottky diode and a $150 \mathrm{~V}$ si pn diode.

\section{DEVICE CHARACTERISTICS - SiC JFETS}

In this section, characterization of a normally-on and normally-off JFETs will be compared to highlight the differences between the two devices.

\section{A. Static Characteristics}

\section{1) Normally-on SiC JFET}

Static characteristics of a (1200 V, 5 A) SiC JFET are shown in Fig. 7 for different operating temperatures. SiC JFETs have a positive temperature coefficient which means that like SiC Schottky diodes, their conduction losses will be higher at higher temperatures. However, a positive temperature coefficient makes it easier to parallel these devices and reduce the overall on-resistance.

The transfer characteristics for 10 different samples of a SiC JFET are shown in Fig. 8. The negative gate pinch-off voltage required to turn-off the device is higher than that required for $\mathrm{Si}$ devices. The earlier generation devices had pinch-off voltages vary between samples. The pinch-off voltages of the newer generation devices do not vary as much. Also, it should be noted that the pinch-off voltage for the newer generation is around $-11 \mathrm{~V}$ compared to the $-22 \mathrm{~V}$ for the previous generation. These are significant improvements which indicate that the SiC JFET technology

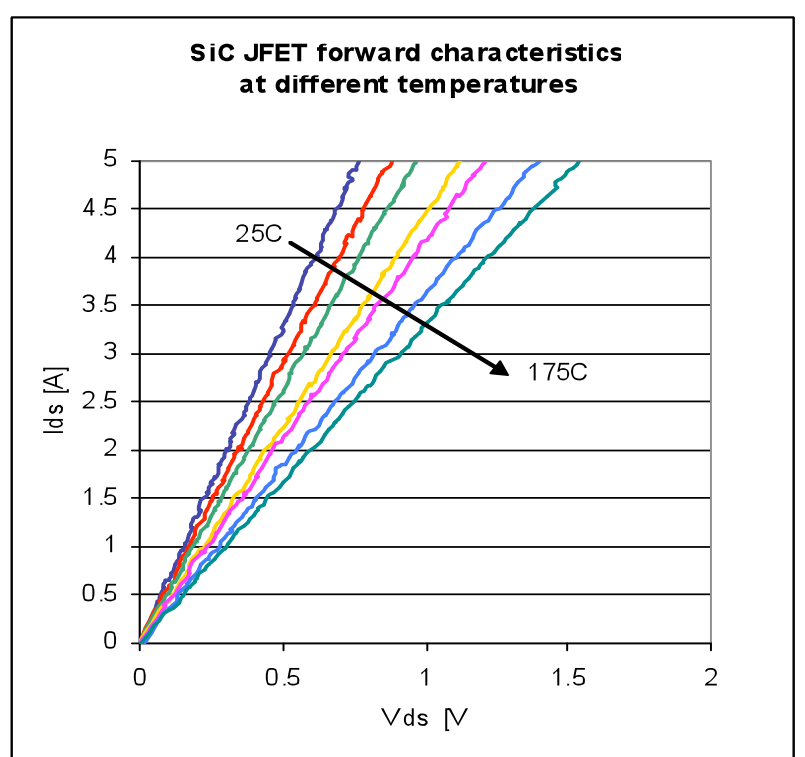

Fig. 7. Forward Characteristics of normally-on SiC JFET.

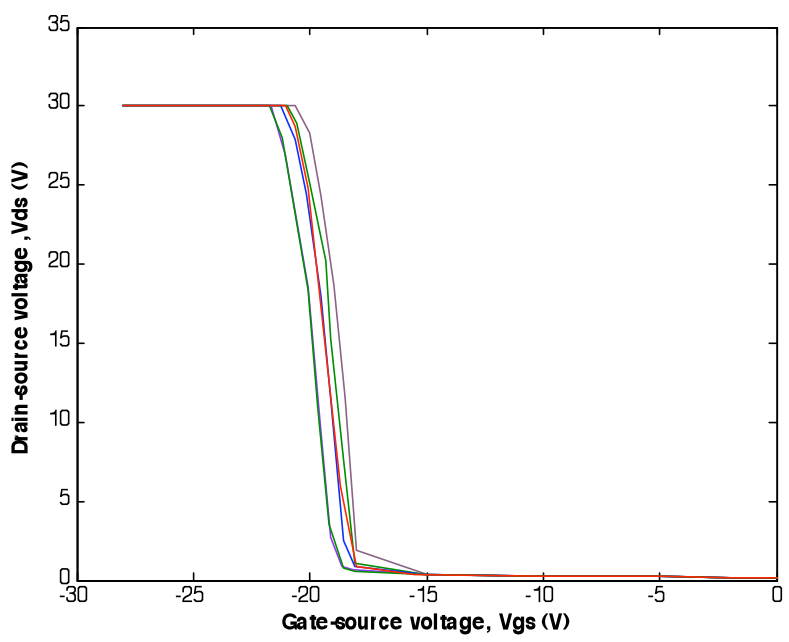

Fig. 8. Transfer characteristics of several normally-on SiC JFET samples.

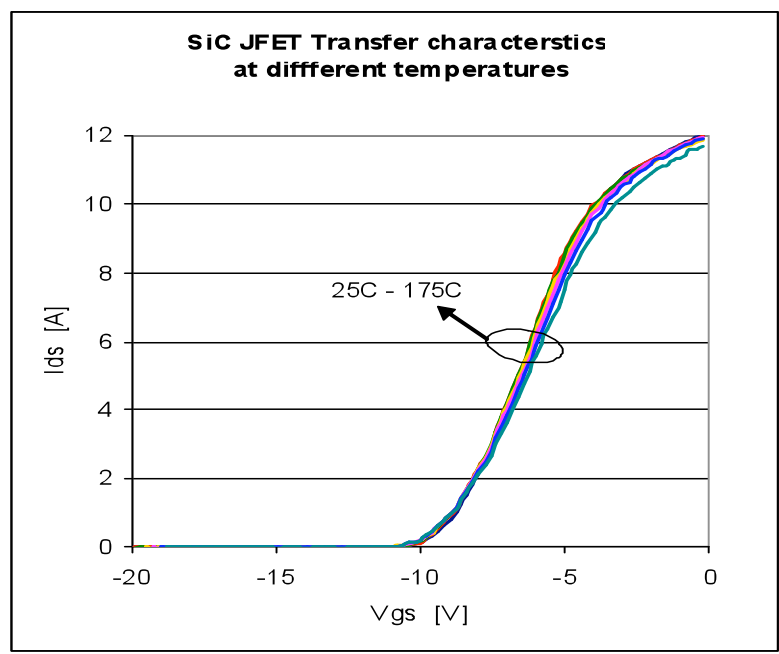

Fig. 9. Transfer characteristics of normally-on SiC JFET at different temperatures. 


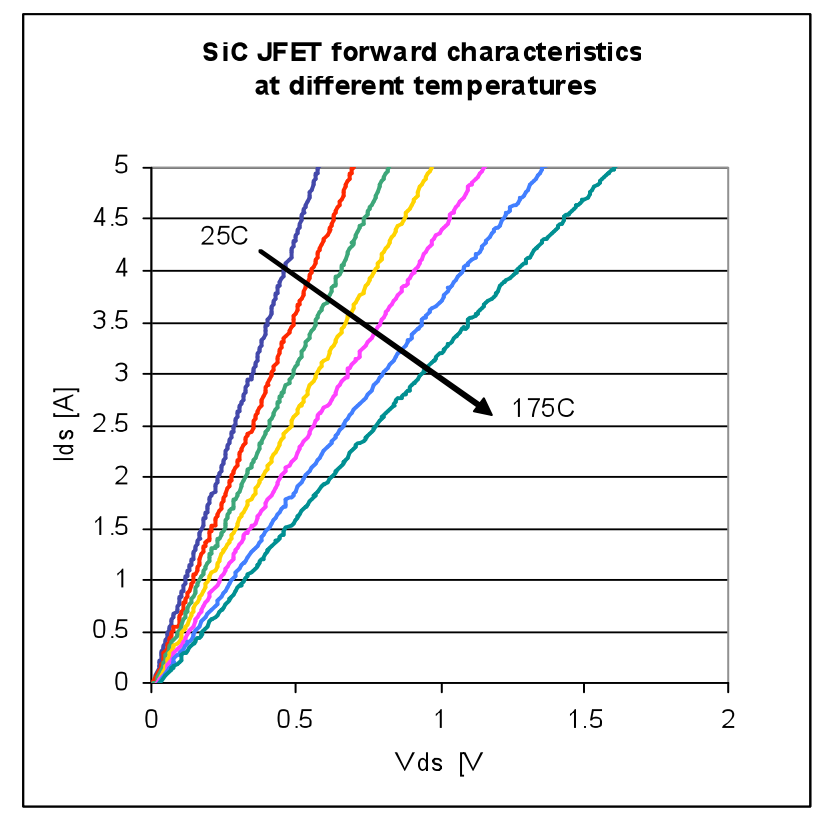

Fig. 10. Forward characteristics of normally off SiC JFET.

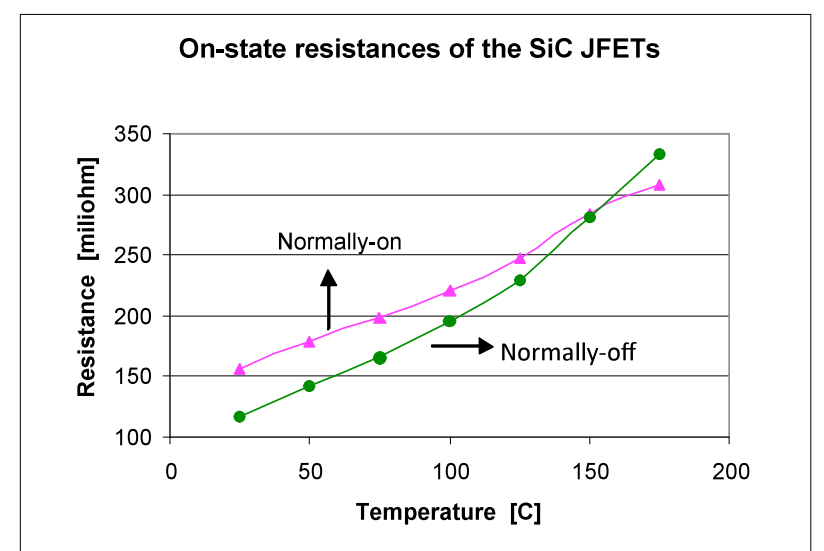

Fig. 11. On-state resistance comparison of normally on and normally off SiC JFETs.

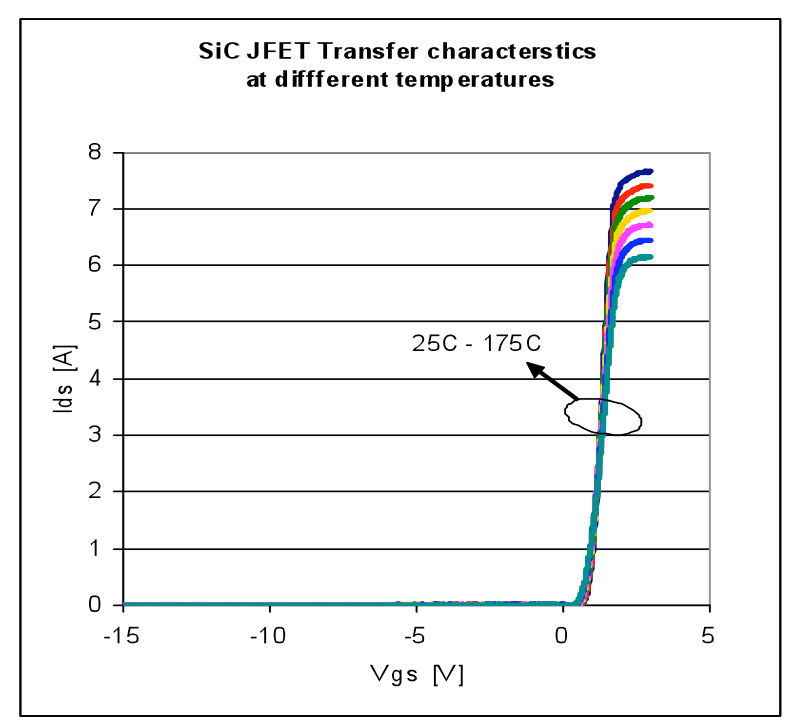

Fig. 12. Transfer characteristics of normally off SiC JFET at different temperatures.

is maturing. The transfer characteristics of the device at different temperatures show the pinch-off voltage does not change with temperature (Fig. 9).

\section{2) Normally-off SiC JFET}

Static characteristics of a $(1200 \mathrm{~V}, 5 \mathrm{~A}) \mathrm{SiC}$ JFET are shown in Fig. 10 for different operating temperatures. The on resistances extracted from the test results of the two JFETs (normally on and normally off) are shown in Fig. 11. The normally-off device has slightly better on-state resistance than the normally-on device. The transfer characteristics of the normally-off JFET are shown in Fig. 12 The threshold voltage does not vary with temperature. The pinch off voltage is much lower for the normally-off device which results in much lower gate drive voltage requirement.

\section{B. Dynamic Characteristics}

\section{1) Normally-on $\mathrm{SiC} J F E T$}

Normally-on devices can be turned off by applying a negative voltage. Based on the transfer characteristics, a gate voltage of $-12 \mathrm{~V}$ has been selected since that would be enough to turn off most of the samples tested. The dynamic characteristics of the JFET were obtained using the high temperature set-up and the double pulse circuit test at several temperatures and currents. The total energy losses of the JFET during switching are shown in Fig. 13. The losses do not change much with temperature.

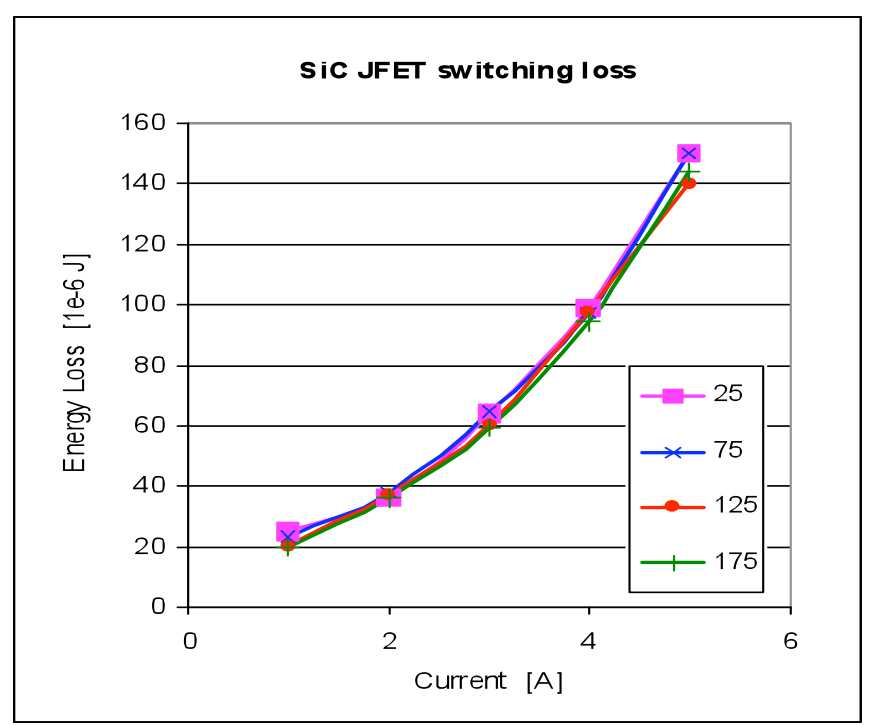

Fig. 13. Switching losses of normally-on JFET.

\section{2) Normally-off SiC JFET}

Normally-off devices need a positive voltage to turn-on the gate channel for maximum current and still need a negative gate voltage to turn-off quickly. Based on the transfer characteristics (Fig. 12), a gate voltage of $+2 \mathrm{~V}$ to $-5 \mathrm{~V}$ has been selected. The dynamic characteristics of the JFET at were obtained using the high temperature set-up and the double pulse circuit test at several temperatures and currents. The total energy losses of JFET during switching are shown in Fig. 14. The losses do not change much with temperature. However, the losses are much higher for similar 
current and temperature compared to the normally-on device. This could be because of the difference in the capacitances of the devices. A comparison of the test results shows that the there is a trade-off between the conduction and switching losses between the two devices.

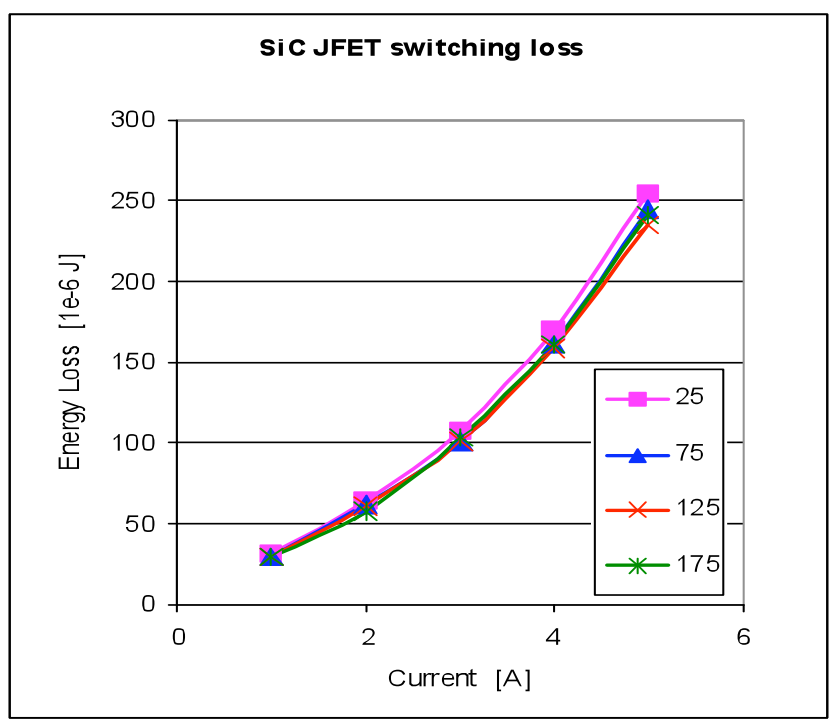

Fig. 14. Switching loss of normally-off SiC JFET at different conditions.

\section{BODY DIODE OF A NORMALLY-ON SiC JFET}

The body diode in a normally-on JFET can be used as the free-wheeling diode in voltage source inverter based applications. By using this diode, the number of devices used in an inverter can be reduced by eliminating the anti-parallel diodes. This diode is only available in some normally-on JFETs. This particular device has a pn diode formed because of the device design.

\section{A. Static Characteristics}

Static characteristics of the body diode in a $1200 \mathrm{~V}, 5 \mathrm{~A}$ SiC JFET for different operating temperatures are shown in Fig. 15. The on-state voltage is much higher than a similar rated Schottky diode [7]. This will make this diode inefficient at higher power levels.

\section{B. Dynamic Characteristics}

The body diode has higher reverse recovery time unlike the zero recovery losses of the Schottky diode which increases the switching losses of the inverter. The reverse recovery characteristics of the body diode at different temperatures are shown in Fig. 16. The peak reverse recovery current increases with increase in temperature. However, the change in current is small resulting in minimal increase in reverse recovery losses at higher temperatures.

\section{SiC MODULE}

The static characteristics of a SiC JFET module at different ambient temperatures $\left(25-200^{\circ} \mathrm{C}\right)$ are shown in Fig.

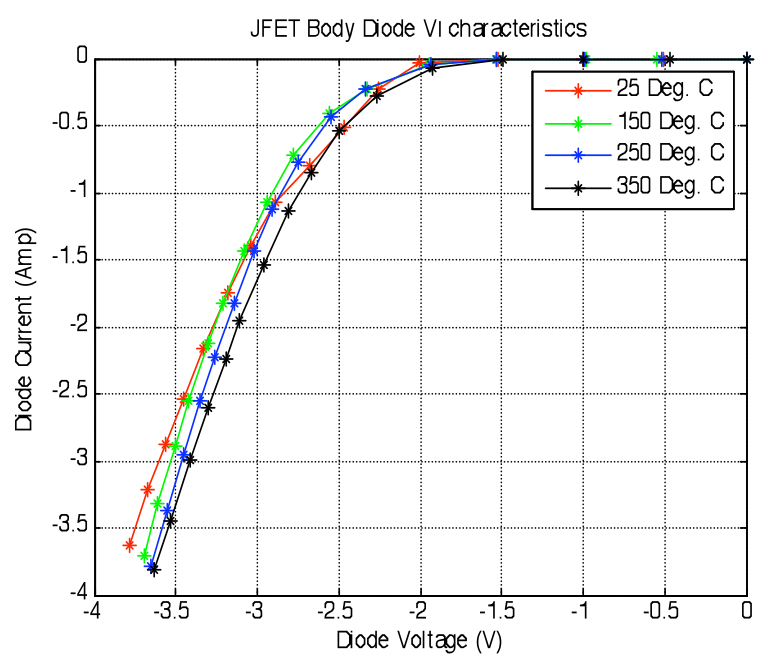

Fig. 15. I-V curves of a SiC JFET.

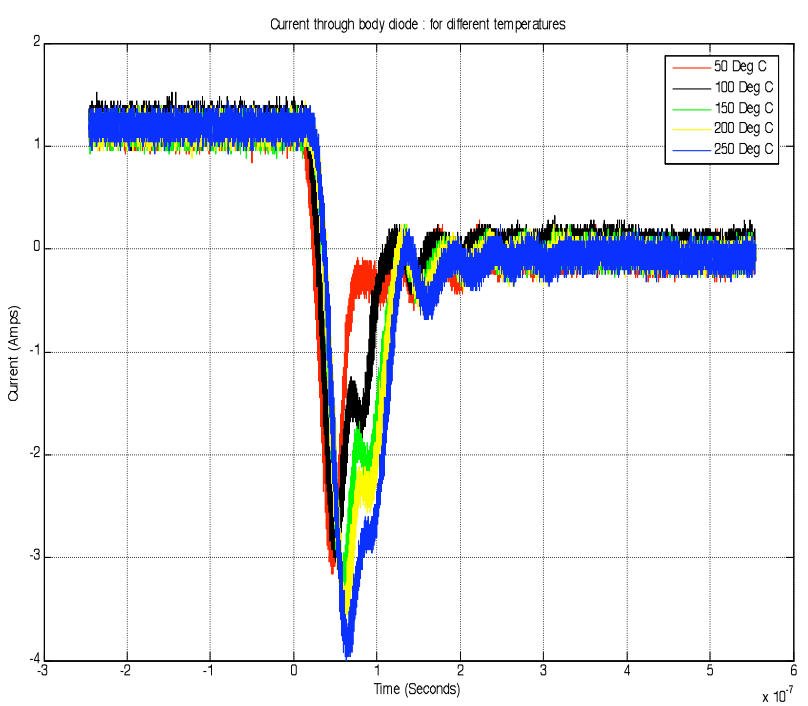

Fig. 16: Reverse recovery characteristics of body diode in a SiC JFET.

17 and Fig. 18. The module consists of three normally-off $1200 \mathrm{~V}$ JFETs at each switch position with a single $1200 \mathrm{~V}$ Schottky diode in antiparallel. The module forms a phase leg for an inverter. The on-state resistances of both JFETs and diodes increase with temperature, while the transfer characteristics of the JFETs are nearly constant in this temperature range (Fig. 19).

Switching tests are also conducted on the module. Commercial gate driver IC HCNW3120 is used to generate 0 $\mathrm{V}$ and $-20 \mathrm{~V}$ to control the JFETs. The peak gate current is 1.6 A when using a gate resistance of $5 \Omega$. In addition, the module was put into the chamber to raise the junction temperature up to $200{ }^{\circ} \mathrm{C}$. As shown in Fig. 20, the switching losses increase with increasing current and are almost constant with increasing temperature. 


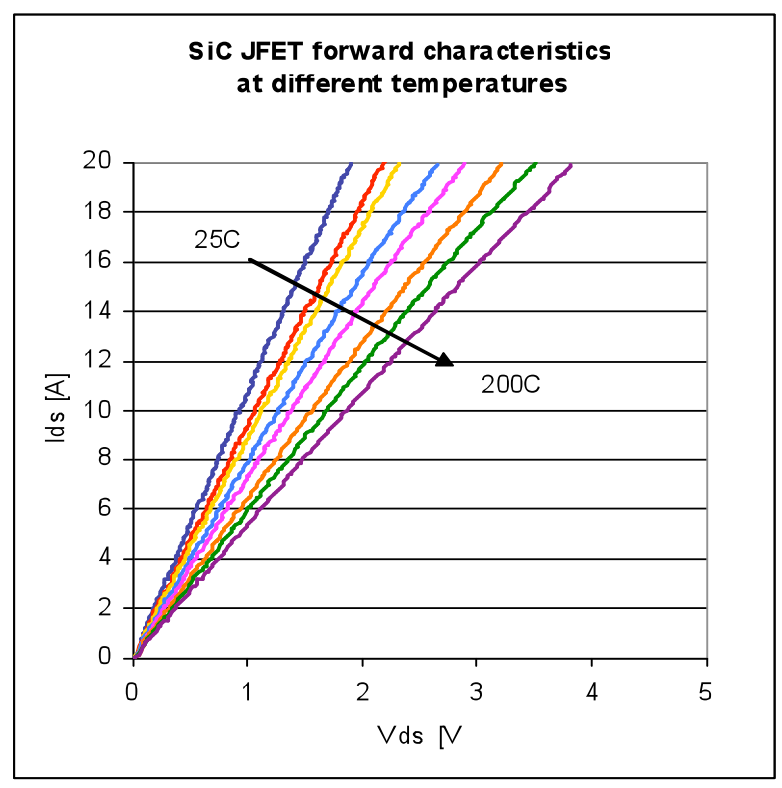

Fig. 17. Static characteristics of paralleled SiC JFETs.

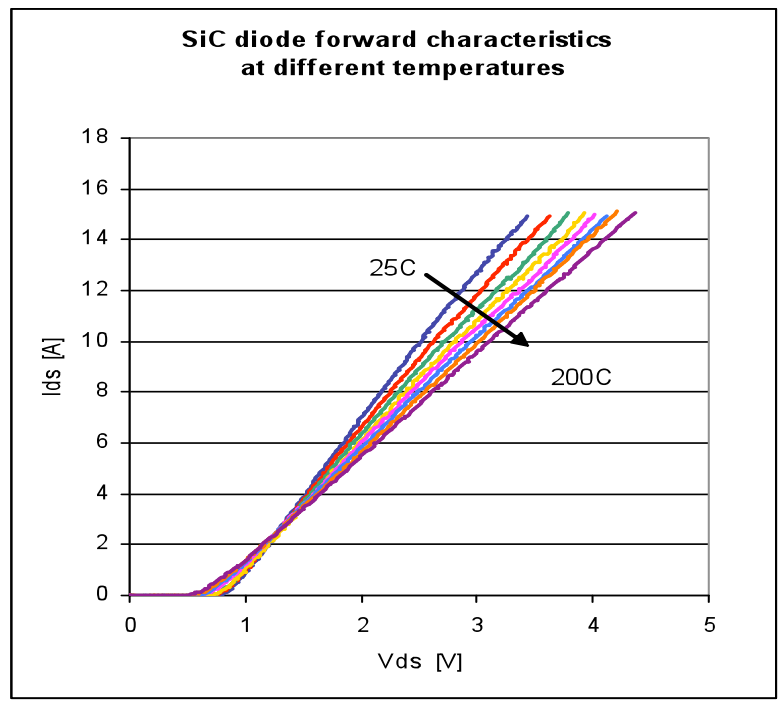

Fig. 18. Static characteristics of paralleled SiC diodes.

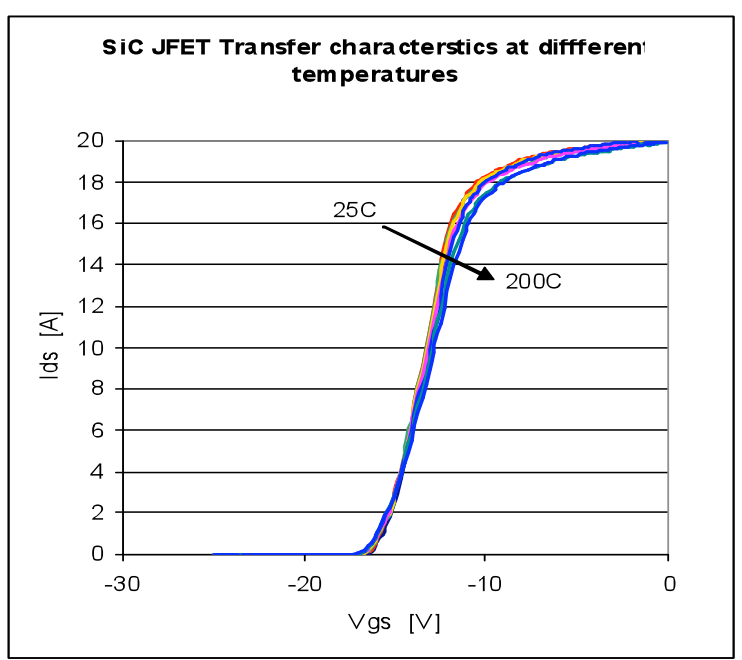

Fig. 19. Transfer characteristics of paralleled SiC JFETs.

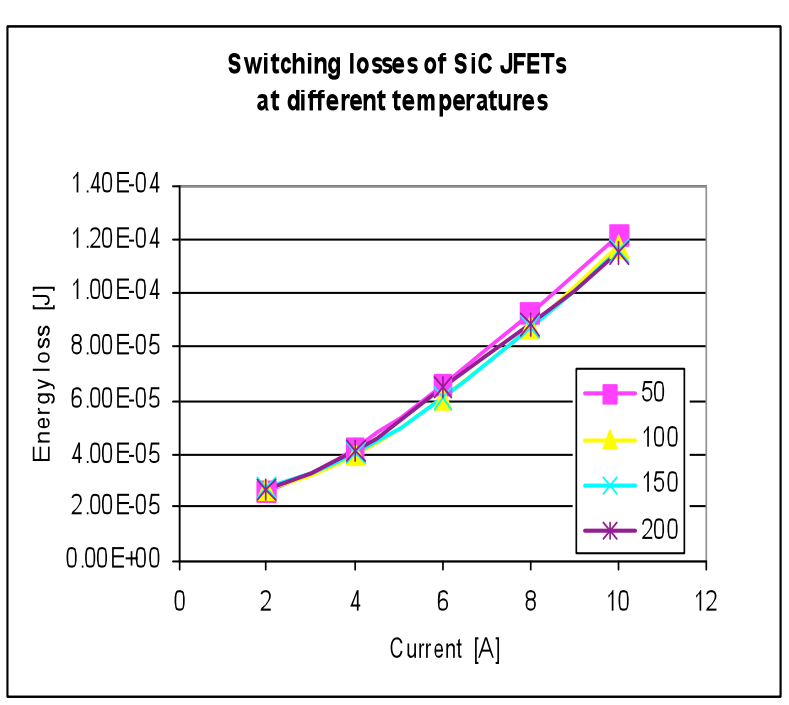

Fig. 20. Switching losses of paralleled SiC JFETs.

\section{HYBRID INVERTER}

A 55kW Automotive Integrated Power Module (AIPM) was built for the U.S. Department of Energy's FreedomCAR Program's hybrid electric vehicle traction drives. These modules contain three-phase inverters with $600 \mathrm{~V} / 600 \mathrm{~A} \mathrm{Si}$ IGBTs and pn diodes.

Cree has developed $600 \mathrm{~V} / 75$ A SiC Schottky diodes. Each Si pn diode in the AIPM was replaced with two of these 75 A SiC Schottky diodes. Both the $\mathrm{Si}-\mathrm{SiC}$ hybrid and the all-Si inverters were tested with an inductive load with the same procedure and the same test and load conditions.

For the inductive load test, the output leads of the inverter are connected to a three-phase star connected variable resistor bank with a three phase inductor bank in series. The dc inputs are connected to a voltage source capable of supplying the maximum rated operating voltage and current levels for the inverter. The dc link voltage was varied from the minimum operating voltage of $200 \mathrm{~V}$ to the maximum bus voltage of $450 \mathrm{~V}$.

The load resistance was set to the minimum value, and the output current was varied. The inverter was operated with a $20^{\circ} \mathrm{C}$ coolant at a flow rate of 9.46 liters per minute. The open loop frequency of operation and the PWM frequency $(10 \mathrm{kHz})$ were fixed and the current command was varied for a particular dc link voltage. For each value of the current command and open loop frequency, the dc link voltage, dc link current, input/output power, efficiency, and output line currents and voltages were recorded. The three-phase power was measured using the two wattmeter method.

The command current was increased in steps of $10 \mathrm{~A}$ without exceeding the power rating of the inverter or the power rating of the load. The procedure was repeated by increasing the open loop frequency in steps of $25 \mathrm{~Hz}$.

The data obtained for both inverters were analyzed, and the corresponding efficiencies were calculated. The efficiency versus output power plots for several operating conditions are shown in Fig. 21. More test results of the inverter is reported in [8]. 


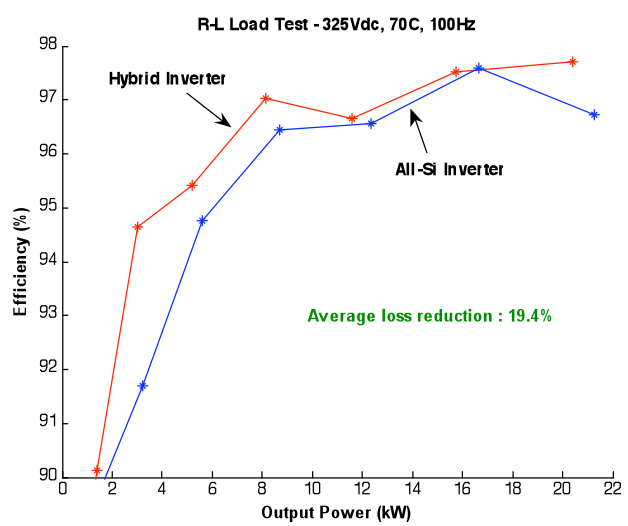

(a)

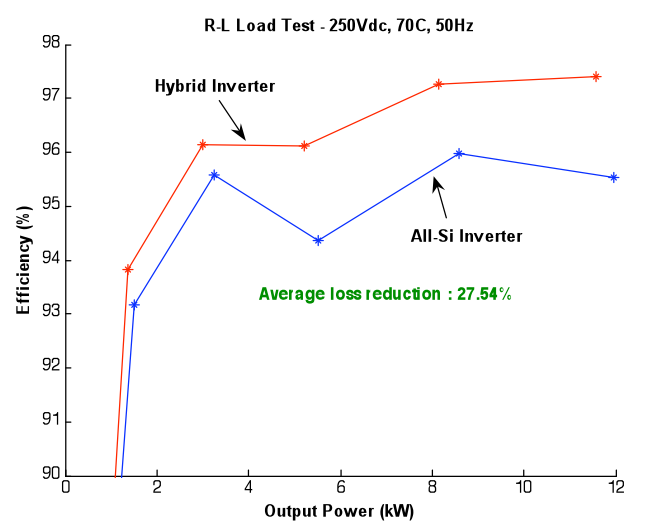

(c)

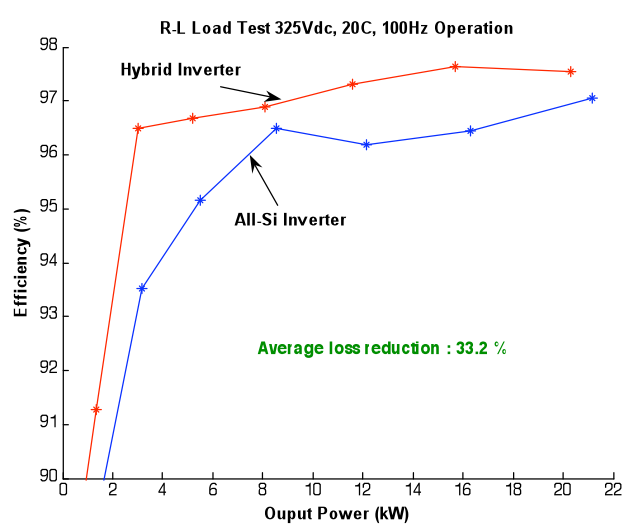

(b)

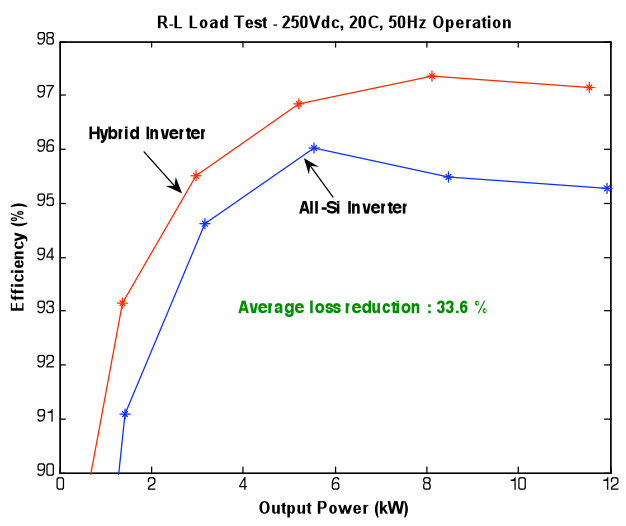

(d)

Fig. 21. R-L load test efficiency curves for various load conditions.

The coolant temperature was changed to $70^{\circ} \mathrm{C}$ and the above procedure was repeated to observe the operation at higher temperatures.

The average loss reduction resulted in using $\mathrm{SiC}$ Schottky diodes instead of Si pn diodes was calculated as:

$$
\% \text { loss reduction }=\frac{P_{\text {loss }}^{S i}-P_{\text {loss }}^{S i C}}{P_{\text {loss }}^{S i}} \times 100 .
$$

The $\mathrm{Si}-\mathrm{SiC}$ hybrid inverter losses are up to $33.6 \%$ less than the all-Si inverter.

\section{SiC INVERTER}

A high efficiency and high temperature SiC JFET inverter phase leg module is shown in Fig. 22. Each module is a single phase leg and is composed of six $1200 \mathrm{~V} \mathrm{SiC} \mathrm{JFETs}$ and two $1200 \mathrm{~V}$ Schottky diodes from SiCED as well as a thermistor to detect the temperature inside the module. Three $\mathrm{SiC}$ JFETs are in parallel in order to achieve a higher current rating $(\sim 30 \mathrm{~A})$. The package is designed to work at a temperature of at least $200{ }^{\circ} \mathrm{C}$ ambient. The module is composed of several layers from top to bottom, they are: $\mathrm{SiC}$ die, silver filled polyimide die attach, $\mathrm{DBC}$ on $\mathrm{BeO}$ (12-mil thick $\mathrm{Cu}$ on both sides of 25 -mil thick $\mathrm{BeO}$ ), silver filled polyimide substrate attach, and Alloy 42 housing with glass hermetic seals. These layers are bonded together through silver filled polyimide die attach material 5-mil diameter aluminum wirebonds. A three phase inverter was built using the three single leg modules shown in Fig. 23.

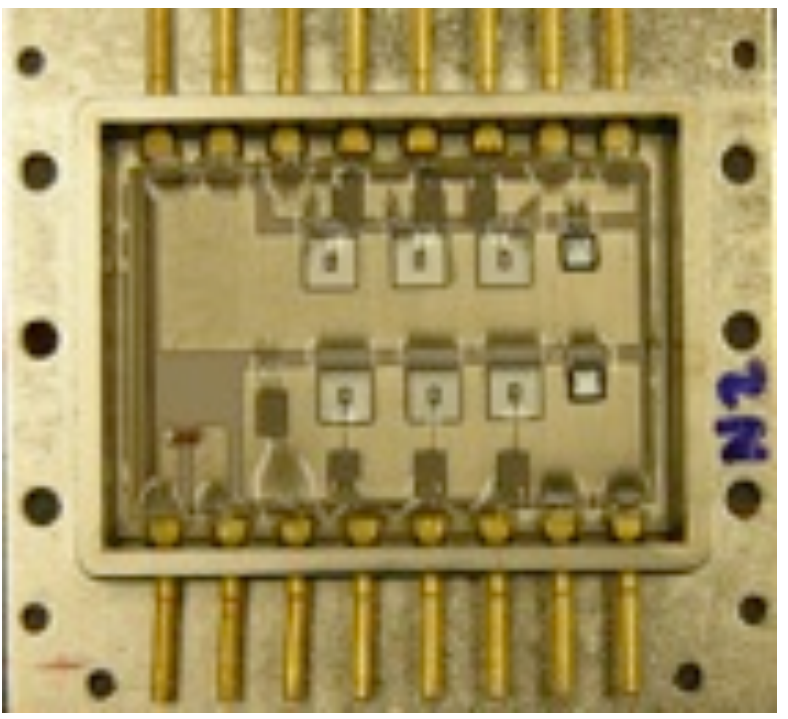

Fig. 22. SiC JFET phase leg module. 


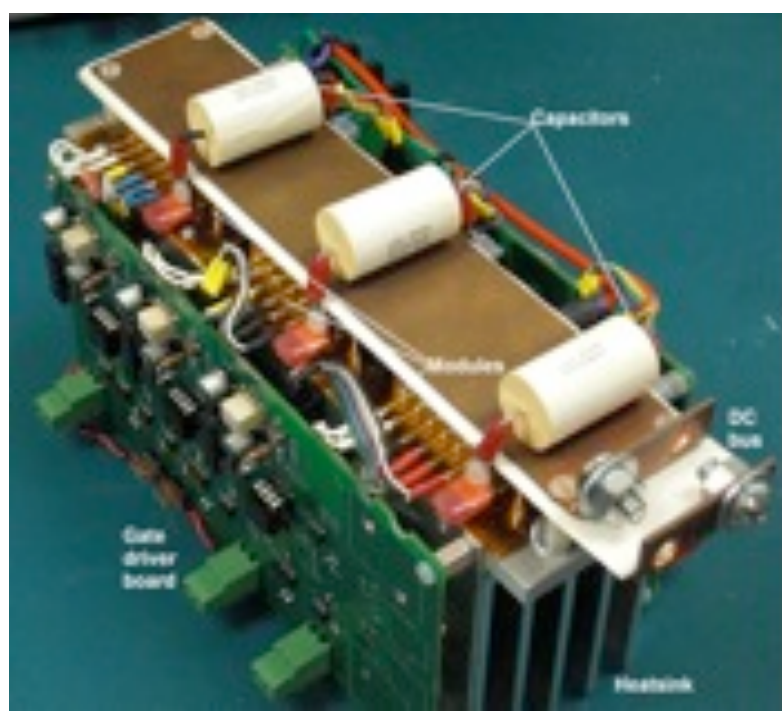

Fig. 23. Prototype SiC JFET inverter.

\section{EXPERIMENTAL RESULTS}

The $\mathrm{SiC}$ inverter developed is tested with an $R L$ load.. The inverter is connected to a DC power supply and feeds ac power to a 3-phase $R L$ load.

It is controlled by SVPWM signals generated by DSP board and the control program is developed in Matlab Simulink. The input DC voltage, current and 3-phase output voltage, current are monitored and measured by oscilloscope and PZ4000.

The efficiency was calculated based on this information. Fig. 24 shows some test results for $60 \mathrm{~Hz}$ fundamental output frequency with a modulation index of 0.8 and three different switching frequencies $(10,15,20 \mathrm{kHz})$. The maximum efficiency, $98.5 \%$, is achieved at a switching frequency of 10 $\mathrm{kHz}$ at $4 \mathrm{~kW}$ output power range. The temperature inside the modules is less than $64{ }^{\circ} \mathrm{C}$ at this operating condition. These test results can be compared to other $\mathrm{SiC}$ inverters reported in [9-11]

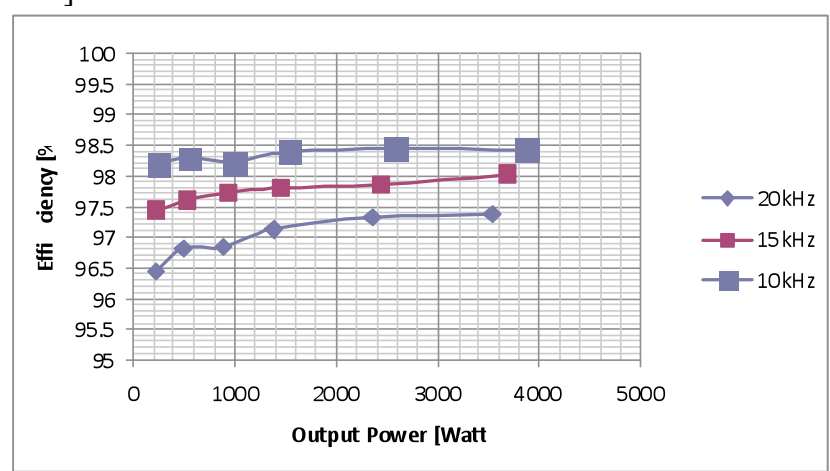

Fig. 24. Efficieny curves of all-SiC inverter.

\section{CONCLUSIONS}

The test results of discrete devices and the devices in the modules were presented and discussed. The results gave an insight to the scaling of the devices for higher power modules. The hybrid inverter test results showed that there is significant improvement in the efficiency when compared to Si-based inverter. The all-SiC inverter had an impressive maximum efficiency of $98.5 \%$ at $4 \mathrm{~kW}$. However, the inverter has to be tested at higher power level to demonstrate similar efficiencies.

\section{REFERENCES}

[1] European Center for Power Electronics (ECPE), "Position paper on energy efficiency - the Role of powerelectronics,"http://www.ecpe.org/download/powerelectr onic/Position_Paper_Energy_Efficiency.pdf, March 2007.

[2] F. Blaabjerg, Z. Chen, "Power electronics as an enabling technology for renewable energy integration," Journal of Power Electronics, vol. 3, no. 2, pp. 81-89, Apr. 2003.

[3] D. Mahoney, L. Casey, "Presentation on high-megawatt converter technology workshop," Proceedings of the High Megawatt Converter Workshop, Gaithersburg, MD, January 24, 2007.

[4] D. Peters, "SiC power devices for industrial inverters," http://siced.com/download/CY5063ab4aX1190ed2 9602XY353c/Abstract_Peters.pdf?ITServ=_CY11cb9072X12 $25 \mathrm{bfb} 7 \mathrm{e} 84 \mathrm{X} 30 \mathrm{c} 6$.

[5] A. Elasser, T.P. Chow, "Silicon carbide benefits and advantages for power electronics circuits and systems," Proceeding of IEEE, vol. 90, no. 6, pp. 969-986, June 2002.

[6] A. R. Hefner, R. Singh, J. S. Lai, D. W. Berning, S. Bouche, and $\mathrm{C}$. Chapuy, "SiC power diodes provide breakthrough performance for a wide range of applications," IEEE Trans. Power Electron., vol. 16, pp. 273-280, Mar. 2001.

[7] L. M. Tolbert, H. Zhang, M. S. Chinthavali, B. Ozpineci, "SiCbased power converters for high temperature applications," Materials Science Forum, vols. 556-557, 2007, pp. 965-970.

[8] B. Ozpineci, M. S. Chinthavali, L. M. Tolbert, "A 55 kW Three Phase Automotive Traction Inverter with SiC Schottky Diodes," IEEE Vehicle Power and Propulsion Conference, September 7-9, 2005, Chicago, Illinois, pp. 541-546.

[9] H. R. Chang, E. Hanna, A. V. Radun, "Demonstration of silicon carbide (SiC)-based motor drive," Annual Conference of the IEEE Industrial Electronics Society, 2003, pp. 11161121.

[10] D. Bergogne, H. Morel, D. Planson, D. Tournier, P. Bevilacqua, B. Allard, R. Meuret, S. Viellard, S. Rael, F. MeibodyTabar, "Towards an airborne high temperature SiC inverter," IEEE Power Electronics Specialists Conference, 2008, pp. 3178-3183.

[11] J. M. Hornberger, E. Cilio, B. McPherson, R. M. Schupbach, A. B. Lostetter, "A Fully Integrated $300^{\circ} \mathrm{C}, 4 \mathrm{~kW}, 3$-Phase, SiC Motor Drive Module," IEEE Power Electronics Specialists Conference, 2007, pp. 1048-1053. 


\section{BIOGRAPHIES}

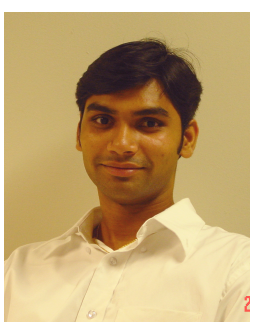

Madhu Sudhan Chinthavali received his M.S. degree in electrical engineering at The University of Tennessee in December 2003. He received a B.E. degree in electrical engineering in 2000 from Bharathidasan University, India. He is currently a R\&D staff member at the Oak Ridge National Laboratory.His areas of interest include wide band gap power semiconductor devices, hybrid electric vehicles, and power system applications.

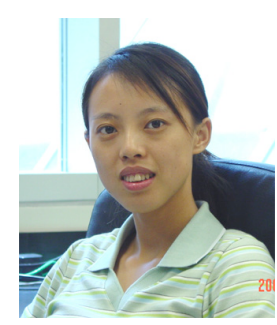

Hui Zhang received a Ph.D. in electrical engineering at The University of Tennessee in December 2007. She received a B.S. and M.S. in Electrical Engineering from Zheijiang University, China, in 2000 and 2003, respectively. She worked as a post-doc at the University of Tennessee from January 2007 until August 2008. Her area of research interest is modeling of silicon carbide based power electronics circuits.

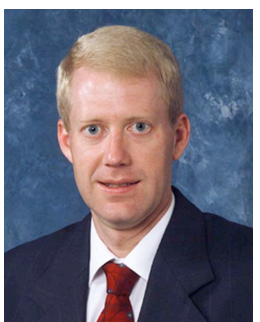

Leon M. Tolbert received the B.E.E., M.S., and $\mathrm{Ph} . \mathrm{D}$. in Electrical Engineering from the Georgia Institute of Technology, Atlanta, Georgia

He joined Oak Ridge National Laboratory in 1991 and worked on several electrical distribution projects at the three U.S. Department of Energy plants in Oak Ridge, TN. In 1997, he became a research engineer in the Power Electronics and Electric Machinery Research Center at the Oak Ridge National Laboratory. In 1999, he was appointed as an assistant professor in the Department of Electrical and Computer Engineering at the University of Tennessee, Knoxville. He is presently the Min Kao Professor in the Min Kao Department of Electrical Engineering and Computer Science. He is a part time employee at the Oak Ridge National Laboratory and conducts joint research at the National Transportation Research Center (NTRC). He does research in the areas of electric power conversion for distributed energy sources, motor drives, multilevel converters, hybrid electric vehicles, and application of $\mathrm{SiC}$ power electronics.

Dr. Tolbert is a registered Professional Engineer in the state of Tennessee. $\mathrm{He}$ is the recipient of three IEEE prize paper awards and the 2001 IEEE Industry Applications Society Outstanding Young Member Award. He is an associate editor of the IEEE Transactions on Power Electronics.

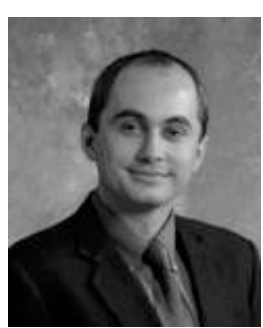

Burak Ozpineci received the B.S. degree in electrical engineering from the Middle East Technical University, Ankara, Turkey, in 1994 and the M.S. and Ph.D. degrees in electrical engineering from the University of Tennessee, Knoxville, in 1998 and 2002, respectively. He joined the Post-Masters Program with the Power Electronics and Electric Machinery Research Center, Oak Ridge National Laboratory (ORNL), Knoxville, TN, in 2001 and became a Full-Time Research and Development Staff Member in 2002 and the Group Leader of the Power and Energy Systems Group in 2008. Presently, he also has an Adjunct Faculty appointment with the University of Arkansas, Fayetteville. He is doing research on the system-level impact of $\mathrm{SiC}$ power devices, multilevel inverters, power converters for fuel cells, $\mathrm{PV}$, and hybrid electric vehicles, and intelligent control applications for power converters.

Dr. Ozpineci is the Chair of the IEEE PELS Rectifiers and Inverters Technical Committee and was the Transactions Review Chairman of the IEEE Industry Applications Society Industrial Power Converter Committee. $\mathrm{He}$ was the recipient of the 2006 IEEE Industry Applications Society Outstanding Young Member Award, 2001 IEEE International Conference on Systems, Man, and Cybernetics Best Student Paper Award, and 2005 UTBattelle (ORNL) Early Career Award for Engineering Accomplishment. 